$$
\text { Conf }-940592--13
$$

\title{
UCRL-JC-117020
}

PREPRINT

\section{Inner-Shell Photo-Ionized X-Ray Laser Schemes for Low-Z Elements}

\author{
S. J. Moon \\ D. C. Eder \\ G. L. Strobel
}

This paper was prepared for submittal to the 4th International Colloquium on $X$-Ray Lasers

Williamsburg, VA

May 16-20, 1994

October 21, 1994

This isa preprint of a paper intended for publication in a journal or proceedings. Since changes may be made before publication, this preprint is made available with the underatanding that it will not be cited or reproduced without the permiesion of the author. 


\section{DISCLAIMER}

This document was prepared as an account of work sponsored by an agency of the United States Government. Neither the United States Government nor the University of California nor any of their employees, makes any warranty, express or implied, or assumes any legal liability or responsibility for the accuracy, completeness, or usefulness of any information, apparatus, product, or process disclosed, or represents that its use would not infringe privately owned rights. Reference herein to any specific commercial product, process, or service by trade name, trademark, manufacturer, or otherwise, does not necessarily constitute or imply its endorsement, recommendation, or favoring by the United States Government or the University of California. The views and opinions of authors expressed herein do not necessarily state or reflect those of the United States Government or the University of California, and shall not be used for advertising or product endorsement purposes. 


\section{DISCLAIMER}

Portions of this document may be illegible in electronic image products. Images are produced from the best available original document. 


\title{
Inner-Shell Photo-Ionized X-Ray Laser Schemes for Low-Z Elements
}

\author{
S. J. Moon ${ }^{* \dagger}$, D. C. Eder ${ }^{*}$ and G. L. Strobel ${ }^{\ddagger}$ \\ * Lawrence Livermore National Laboratory, Livermore, CA 94550 \\ $\dagger$ Department of Applied Science, University of California Davis-Livermore, Livermore, CA 94550 \\ $\ddagger$ Department of Physics, University of Georgia, Athens, GA
}

\begin{abstract}
Gain calculations for inner-shell photo-ionized lasing in $C$ at $45 \AA$ are performed. An incident $x$-ray source represented by a $150 \mathrm{eV}$ blackbody with a rise time of $50 \mathrm{fsec}$ gives a gain of order $10 \mathrm{~cm}^{-1}$. The $\mathrm{x}$-ray source and thus the driving optical laser requirements are significantly reduced as compared to what is needed for $\mathrm{Ne}$ at $15 \AA$. We expect that existing ultra-short pulse lasers can produce the required $\mathrm{x}$-ray source and thus produce a table-top $x$-ray laser at $45 \AA$.
\end{abstract}

\section{INTRODUCTION}

Previous theoretical work in inner-shell photo-ionized (ISPI) laboratory $\mathrm{x}$-ray laser schemes have mainly focused on the 5 to $15 \AA$ wavelength regime, where laboratory $\mathrm{x}$-ray lasing using any approach has not yet been obtained. This was investigated for $\mathrm{Ne}$ at $15 \AA$ by Kapteyn[1] and extended by Strobel $e$ t al.[2] also treating $\mathrm{Mg}$ at $10 \AA$. The experimental validation at these short wavelengths is dependent on the development of an ultra-short pulse (100 fsec FWHM) optical laser with energy of order $10 \mathrm{~J}$ or greater. Current "table-top" size ultra-short pulse (USP) lasers with energy of order $1 \mathrm{~J}$ exist. We present results for C at $45 \AA$ as a representative low- $Z$ element where lasing can be tested experimentally using current high energy ultra-short pulse lasers. Carbon has a smaller Auger rate compared with $\mathrm{Ne}$ and a longer lasing wavelength thus requiring a less energetic pump source. An $x$-ray laser at $45 \AA$, just outside the water window, is optimal for many biological applications[3].

Although current $\mathrm{x}$-ray lasers using $\mathrm{Ni}$-like ions operate at above and below the wavelength considered in this paper, $45 \AA$, they require high energy $(E>1 \mathrm{~kJ})$ driving lasers[4]. As a result of using a lower energy driving laser $(E \approx 1 \mathrm{~J})$, an inner-shell $x$-ray laser would operate at a higher repetition rate, albeit with less energy in each $x$-ray pulse. Despite a very short lasing duration $(\Delta t<100 \mathrm{fsec})$ and small cross sectional area $\left(A=10^{-6} \mathrm{~cm}^{2}\right)$, the large saturation intensity, $I_{\text {sat }}$, associated with the relatively large Auger rate out of the upper lasing state[5] results in significant energy per pulse yielding a high average energy.

In the ISPI scheme, lasing takes place between the $\mathrm{L}$ shell and the $\mathrm{K}$ shell. Neutral Ne having a closed L shell makes it a good candidate for ISPI lasing, yet 
current lasers can not provide the needed energy to produce a significant gainlength product[1]. Because of the open $L$ shell structure in $C$, it is relatively easier to both collisionally- and photo-ionize the $\mathrm{L}$ shell thus destructive filling of the lower-lasing state is more severe for $\mathrm{C}$ than Ne. Due to the lower energy requirements for $\mathrm{K}$-shell ionization of $\mathrm{C}$ and the smaller Auger rate the requirement on the intensity of the pump is reduced as compared to Ne; however, the rise time requirements are not changed. A blackbody source is chosen to represent the $\mathrm{X}$-ray source yet by optimizing the target material it may be possible to use a line or band source which would give more efficient pumping.

In section II we discuss general details of the ISPI scheme first proposed 25 years ago by Duguay and Rentzepis[6]. In section III we report our results for $\mathrm{C}$ at $45 \AA$ and in section IV discuss conclusions.

\section{INNER-SHELL PHOTO-IONIZATION}

An USP (100 fsec FWHM) optical laser with energy $\geq 1 \mathrm{~J}$ is used to produce a hot plasma at line focus. The plasma generates a broad-band $x$-ray spectrum with a rapid rise time. A low- $Z$ filter is sandwiched between the target and lasant to stop a majority of the low energy $x$ rays that can ionize outer-shell electrons and thus populate the lower-laser state. The remaining high energy $x$ rays primarily photoionizes the inner-shell electrons of the lasant atoms. This produces a population inversion, and resulting positive gain for an allowed $2 \mathrm{p}-1 \mathrm{~s}$ radiative transition in the singly charged ion for a sufficiently intense $\mathrm{x}$-ray source. Rapid Auger decay of the $1 \mathrm{~s}$ hole state competes with the lasing transition and produces a large number of energetic electrons into the lasant material. Electron induced ionization to the lower-laser state limits the magnitude and duration of positive gain. Ultra-short pulse $x$-ray lasing is inherent in this scheme.

A high intensity source of $\mathrm{x}$ rays is required to compete with the Auger rate and cause a significant upper-laser state population. To achieve a high absorption of the driving laser's energy a structured target, parallel grooves on a solid material, or a composite of clusters, e.g., gold-black, can be used[7]. The cluster targets are relatively inexpensive to produce but difficult to model due to their fractal properties. A new inexpensive structured target consisting of vertical rods[8] has been shown to also have high absorption properties[9]. We are currently modeling this type of target, but in this paper we concentrate on gain calculations for an assumed $\mathrm{x}$-ray source.

A time dependent single temperature blackbody is used to approximate the $\mathrm{x}$-ray emission from the plasma. For work done using a Au target composed of parallel grooves this is shown to be a conservative assumption[10]. An ideal source would be a line source with the difference in energy with the lasant's $\mathrm{K}$ edge being within the L-shell energy. This provides maximum coupling of $\mathrm{x}$-ray energy to the lasant atoms, because the cross-section is peaked at threshold. In addition, such a line source would effectively reduce electron ionizations of the $L$ shell from photo-ionized electrons. In the lasing medium, electrons come from both photon ionization and from Auger decay. The energy spectrum of the photoionized electrons is dependent on the $\mathrm{x}$-ray source. As stated above an optimized source can mitigate this problem. However, the negative effect of Auger electrons 
will not be affected. If the rise time of the $\mathrm{x}$ rays is rapid enough, lasing can be achieved before significant electron ionization can occur.

To achieve lasing a filter is needed in order to reduce the low energy $\mathrm{x}$ rays. A low-Z filter can be chosen to optimize the ratio of the $\mathrm{x}$ rays at $\mathrm{K}$-shell energies to $\mathbf{x}$ rays at the L-shell energies in the lasant. Filtering is primarily through K-shell ionization of the low-Z filter element. For $\mathrm{Ne}$ it was found that 3.5 microns of $\mathrm{Be}$ with $E_{K}=118.4 \mathrm{eV}$ yield maximum gain. In $\mathrm{C}$, we find that 2 microns of $\mathrm{Li}$ with $\mathrm{E}_{\mathrm{K}}=59.9 \mathrm{eV}$ is optimal. This thickness does result in a reduction of $\mathrm{x}$ rays at the $\mathrm{K}$ edge of $\mathrm{C}$ by $60 \%$. However this is required to sufficiently reduce the amount of lower energy $x$ rays. There are windows of high transmission below the filter's $\mathrm{K}$-edge energy and a trade-off is made between filtering at the lasant's $\mathrm{K}$ edge to reduce the low energy photons enough for lasing to occur. Geometrical effects associated with the plasma being a line source of finite transverse extent and with the separation between the plasma and the lasant given by the filter thickness are included in our calculations.

\section{RESULTS}

Previous work $[1,2]$ has shown that for gains of order $10 \mathrm{~cm}^{-1}$ in $\mathrm{Ne}$, a maximum blackbody temperature of order $500 \mathrm{eV}$ with rise time of $50 \mathrm{fsec}$ is required. We find that for $C$ a much reduced blackbody temperature $\left(T_{b b} \approx 150 \mathrm{eV}\right)$, with the same $50 \mathrm{fsec}$ rise time, gives comparable gains. Shown in fig. 1 are blackbody spectrums appropriate for $\mathrm{Ne}$ and $\mathrm{C}$. The filtered spectrum is also shown with the $\mathrm{K}$ edges marked for reference. As can be seen for both Ne and $\mathrm{C}$ the peak of the filtered spectrum is to the right of the $\mathrm{K}$ edge allowing for the broad band nature of the filtered spectrum to be taken advantage of. However, the cross section decays rapidly from its maximum value at the $\mathrm{K}$ edge, for example, in $\mathrm{C}$ at the peak of the filtered spectrum the cross section is $1 / 4$ of its $\mathrm{K}$-edge value, where as the filtered spectrum only increases by a factor of 2 of its $\mathrm{K}$-edge value. This results in the convolution of the intensity and the absorption cross-section having a peak very near the $\mathrm{K}$ edge and decreasing monotonically for higher energies. The replacement of the broad-band source with a line source near the $\mathrm{K}$ edge or a
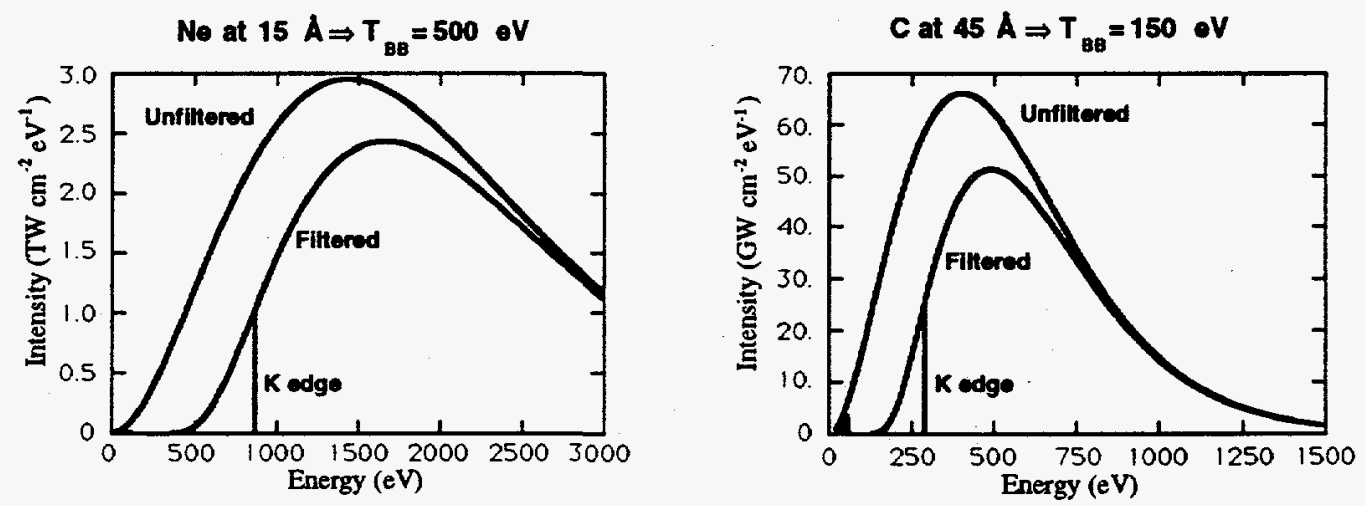

FIGURE 1. X-Ray source requirements for both $\mathrm{Ne}$ at $15 \mathrm{~A}$ and $\mathrm{C}$ at $45 \AA$. The filtered source for Ne uses a $3.5 \mu \mathrm{m}$ Be filter and for $\mathrm{C} \mathrm{a} 2 \mu \mathrm{m} \mathrm{Li}$ filter is used. 
band of emission above the $\mathrm{K}$ edge would reduce the requirements on the source. For a line source at the $\mathrm{K}$ edge the flux required for the $\mathrm{x}$-ray source is approximately $1 / 6$ that of the $150 \mathrm{eV}$ broad-band source.

For the time dependence of the $\mathrm{x}$-ray source we use a simple expression appropriate for a $\operatorname{sech}^{2}$ driving pulse[1]. Expressed in terms of a blackbody temperature it is given by the equation,

$$
T_{b b}=T_{M a x}\left[0.02 \int_{-\infty}^{t} \operatorname{sech}^{2}\left(1.76 t^{\prime} / \tau\right) d t^{\prime}\right]^{4 / 9} .
$$

where $\tau$ is the FWHM of the driving laser and $T_{\max }$ is the maximum temperature (model assumes no cooling). This is shown in fig. 2 for $T_{\max }=150 \mathrm{eV}$ and $\tau=$ $50 \mathrm{fsec}$ which are appropriate parameters for $\mathrm{C}$. The corresponding gain curve in fig. 2 is for a neutral $C$ density of $4.0 \times 10^{19} \mathrm{~cm}^{-3}$ mixed with $4 \mathrm{H}$ atoms for every $\mathrm{C}$ atom. Molecular effects of $\mathrm{CH}_{4}$ were not treated. The $\mathrm{x}$-ray source is taken to have a traverse extent of $10 \mu \mathrm{m}$ used in conjunction with a $2 \mu \mathrm{m} \mathrm{Li}$ filter. Results for $C$ using a driving laser with $\tau=100$ fsec show a reduction in gain by a factor of 3. As shown in fig. 2, the gain has a FWHM of $\approx 60 \mathrm{fsec}$, showing the ultrashort pulse nature of this scheme. In fig. 3, the populations of the upper- and lower-laser states are plotted with the filtered intensity of the x-ray source. From this plot we can see that the upper-laser state population follows the intensity which is expected given the fast Auger exit channel out of the upper state. This will be the case unless the intensity changes on a time scale faster than the inverse of the Auger rate which for $\mathrm{C}$ is $10.7 \mathrm{fsec}$. The lower-laser state population grows exponentially due to electron-ionizations. Since the degeneracy between the lower- and upper-laser states is 3 to 1 , the gain goes to zero when the lower-state population reaches three times the upper-state population.

Given the calculated gain coefficient, a line source of $x$ rays with a length of order $1 \mathrm{~cm}$ is required in order to have a gain-length product of order 10. (Gain-length products between 5 and 10 provide clear evidence of lasing.) Assuming a conversion efficiency to incoherent $x$ rays of $20 \%$, the energy required for the

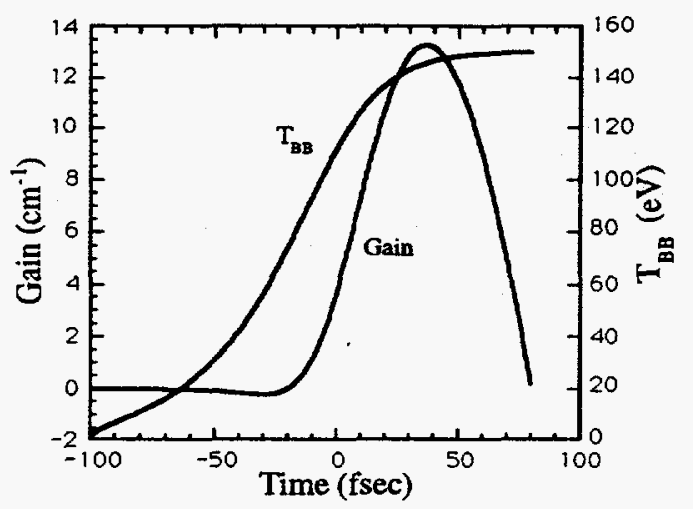

FIGURE 2. A gain coefficient of $13 \mathrm{~cm}^{-1}$ with $F W H M=58$ fsec is shown for $C$ with $T_{\max }=150 \mathrm{eV}$ time dependent blackbody source.

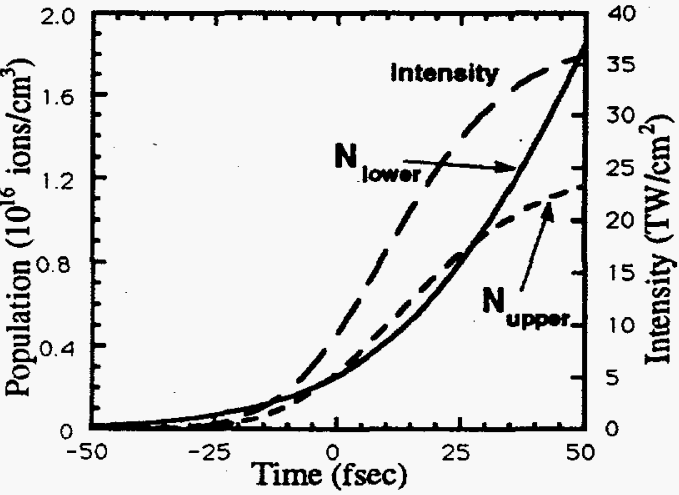

FIGURE 3. Time dependent plots of the upper- and lower-laser state populations leading up to max. gain are shown along with the fittered intensity of the source. 
driving laser is $1.0 \mathrm{~J}$. Lasers with this energy are currently available. The major issue is whether the rise time of the $x$ rays is sufficiently rapid $(\tau=50 \mathrm{fsec})$ since this can not be currently measured.

\section{CONCLUSIONS}

Theoretical work on inner-shell photo-ionized x-ray lasers in the 5 to $15 \AA$ wavelength regime shows that the equivalent blackbody temperature of the $\mathrm{X}$-ray source must be of the order $500 \mathrm{eV}$, requires a driving laser with energy of order $10 \mathrm{~J}$ or greater. Our preliminary results for $\mathrm{C}$ at $45 \AA$ indicated a driving laser with energy of order $1 \mathrm{~J}$ is sufficient to produce a large gain-length product. Gains of over $10 \mathrm{~cm}^{-1}$ were found for $C$ of a density of $4.0 \times 10^{19} \mathrm{~cm}^{-3}$ using a $2 \mu$ $\mathrm{Li}$ filter and a maximum black-body temperature of $150 \mathrm{eV}$ pumped with $50 \mathrm{fsec}$ rise time. Collisional ionization to the lower lasing levels limits the duration of lasing giving a pulse on the order of $60 \mathrm{fsec} F W H M$. Such short coherent $x$-ray emission is important for many applications involving fast dynamical processes.

\section{Acknowledgments}

Work performed under the auspices of the U. S. Department of Energy by Lawrence Livermore National Laboratory under Contract W-7405-ENG-48

\section{References}

1. H. C. Kapteyn, Applied Optics 31, 4931 (1992).

2. G. L. Strobel, D. C. Eder, R. A. London, M. D. Rosen, R. W. Falcone, and S. P. Gordon, SPIE Proceedings, Short-Pulse High-Intensity Lasers and Applications II, L.A., CA, Jan. 1993, Vol. 1860 p. 157.

3. R. A. London, M. D. ROsen, and J. E. Trebes, Applied Optics 28, 3397 (1989).

4. X-Ray Lasers 1992, Proceedings of the 3rd International Colloquium on X-Ray Lasers, IOP Conference Series 125, edited by E. E. Fill (Institute of Physics, Bristol, England, 1992).

5. G. L. Strobel, D. C. Eder, and P. Amendt, Appl. Phys. B, 58, 45 (1994).

6. M. A. Duguay and P. M. Rentzepis, Appl. Phys. Lett. 10, 350 (1967).

7. M. M: Murname, H. C. Kapteyn, S. P. Gordon, J. Bokor, E. N. Glytsis, R. W. Falcone, Appl. Phys. Lett. 62, 1068 (1993).

8. D. Al-Mawlawi, C. Z. Liu, and Martin Moskovits, J. Mater. Res. 9, p. 1014 (1994).

9. F. Budnik, G. Kulcsár, L. Zhao, R. Marjoribanks, P. Herman, D. Al-Mawlawi, M. Moskovits, 24th Anomalous Absorption Conference, Pacific Grove, CA, June 1994.

10. D. C. Eder, G. L. Strobel, R. A. London, and M. D. Rosen, SPIE Proceedings, Applications of Laser Plasma Radiation, San Diego, CA, 1993, edited by M.

Richardson (SPIE, Bellingham, WA, 1994), Vol. 2015, p. 234. 